\title{
Editorial
}

\section{On authorship, mentorship and responsibility for data accuracy}

In an editorial in the first issue of Science in $2010^{(1)}$, Editorin-Chief, Bruce Alberts, writes: 'The scientific enterprise is built on a foundation of trust'. The author emphasizes the importance of maintaining high ethical standards in any scientific publishing. He points to a previous publication in Science $^{(2)}$, where he and colleague Kenneth Shine pushed for a 'research environment that, through its adherence to high ethical standards and creative productivity, will attract and retain individuals of outstanding intellect and character...' In the recent editorial, Alberts discusses two main topics. The first is discouraging 'honorary authorships', and the second is that the senior author for each group should take personal responsibility for what is published. Alberts also points to the publication On Being a Scientist: Third Edition ${ }^{(3)}$ from 2009, freely downloadable from the National Academies Press.

\section{Authorship}

Public Health Nutrition is following the guidelines published by the Committee on Publication Ethics (COPE) ${ }^{(4)}$. The online document from COPE, named 'How to handle authorship disputes: a guide for new researchers', is especially relevant. This document quotes the International Committee of Medical Journal Editors from 2001:

Authorship credit should be based only on:

(1) substantial contributions to conception and design, or acquisition of data, or analysis and interpretation of data;

(2) drafting the article or revising it critically for important intellectual content; and

(3) final approval of the version to be published.

Conditions (1), (2), and (3) must all be met. Acquisition of funding, the collection of data, or general supervision of the research group, by themselves, do not justify authorship.

The publication On Being a Scientist ${ }^{(3)}$ specifies the importance of intellectual contribution, saying that 'providing laboratory space for a project or furnishing a sample used in the research is not sufficient...'. Being hired to do a particular job does not automatically qualify to authorship either.

\section{Author AND project co-ordinator AND grant writer}

Can the guidelines for authorship possibly become an issue for senior scientists as well as for younger women?
Senior scientists are often responsible for educational programmes, supervision of staff, financial reporting, grant writing and - linked to the grant writing - for the final reporting of projects. Junior women may be spending some of their earlier career years on maternity leave. Adding to this the uneven distribution of family and home tasks, a major problem of fairness related to time and work burden arises. Those burdened with all or some of these (for science and for the survival of the scientist's family) very important tasks will sooner or later run into issues regarding authorship, having been run over by colleagues wanting to publish as soon as possible, not taking into account the time constraints of others.

\section{Helpful guidelines from COPE}

Those who are busy writing reports to funding bodies after data collection are directly dependent on having written guidelines before data are collected, identifying who writes what and also providing a reasonable timeline for publications. If such an agreement is not made beforehand, PhD students and other colleagues not caught up in the report writing/educational tasks/staff supervision/family care will go ahead with the writing and there is an obvious risk of disagreements.

A solution could be always to produce, at the beginning of small or big projects, an early document on who publishes what and when. A delay in when papers are published will inevitably be the result of a fairer view on the contribution to writing and publishing, making it possible to have all authors' involvement in the revision and in the final approval of the manuscript. The guidelines from COPE are providing excellent food for thought in this regard ${ }^{(4)}$.

Another solution is to use a mentoring approach, suggested by Alberts ${ }^{(1)}$. This would mean that another kind of recognition could be given to senior scientists who see their role as more mentoring than writing. As Alberts suggests, when used this could then be included in PubMed and thereby reward such mentors, perhaps being included as a significant part of a senior scientist's portfolio.

\section{Who takes responsibility for the data published?}

According to the recent editorial by Alberts $^{(1)}$, Science will require that the senior author for each group confirms that the original data are appropriately presented. 
This means that it is often not ONE single author who is responsible for the content in each paper; it is a group of senior scientists when the publication is a result of collaboration between groups with different expertise and nationalities. Development of new guidelines on responsibility with regard to research integrity is highly relevant to recent developments wherein international and cross-disciplinary collaboration is prevailing. The responsibility for original data in this regard will be discussed further in this journal and by COPE.

Agneta Yngve Editor-in-Chief

\section{References}

1. Alberts B (2010) Promoting scientific standards. Science 327, 12 .

2. Alberts B \& Shine K (1994) Scientists and the integrity of research. Science 266, 1660-1661.

3. Committee on Science, Engineering, and Public Policy, National Academy of Sciences, National Academy of Engineering \& Institute of Medicine (2009) On Being a Scientist: Third Edition. Washington, DC: National Academies Press; available from http://www.nap.edu/catalog. php?record_id=12192.

4. Albert T \& Wager E (2003) How to handle authorship disputes: a guide for new researchers. http:// publicationethics.org/files/u2/2003pdf12.pdf （accessed February 2010). 